\title{
Awareness on the Management of Jaw Fractures in Osteoporotic patients among Dental Students - A Survey
}

\author{
Nur Liyana Hannah Binti Izham Akmal' and Dhanraj Ganapathy ${ }^{2}$ \\ ${ }^{1}$ Saveetha Dental College, Saveetha Institute of Medical and Technical Science, \\ Saveetha University, Tamil Nadu, India \\ ${ }^{2}$ Professor and Head, Department of Prosthodontics Saveetha Dental College, Saveetha \\ Institute of Medical and Technical Science, Saveetha University, Tamil Nadu, India
}

\section{ABSTRACT}

Osteoporosis is one of the common health problems affecting 5\% of the population globally. It is often described as a metabolic bone disease with bone fragility and high risk of fracture resulting from reduced bone mass, microarchitectural weakening of the bone. It affects all bones in the human body including the facial skeleton which often results in jaw fracture. Management of mandibular fracture in osteoporotic wounds is similar to that of other fractures which may be in the form of closed reduction or open reduction, in addition to other forms of treatments such as antibiotic therapy. The aim of this study is to evaluate the awareness of dental students on the various management of jaw fractures in osteoportic patients. A questionnaire-based study was done involving 100 participants. The inclusion criteria of this study were dental students ranging from third years to postgraduates with personal experiences of working in a dental setting. Questions related to the awareness on the management of jaw fractures in osteoporotic wounds were provided. Data was collected and analyzed using the SPSS version 23.0.

Change in occlusion is the most common physical finding of jaw fracture (23\%) and angle fracture is considered to have the highest rate of complications (37\%) that can be treated with extraoral ORIF with a large reconstruction plate (39\%). Complications of fracture treatment are usually associated with infections (71\%). Comminuted fracture of mandible can be best treated with reconstruction plates (74\%), while open reduction with internal fixation is often done for edentulous mandible (68\%). Locking reconstruction plates provide no intimate contact with the underlying bone (42\%). Transoral approach is usually preferred for jaw fracture (39\%) and open reduction of condyle fracture is often performed with preauricular incision (77\%). Lateral extracapsular displacement is selected as the absolute indication for open reduction of condyle fracture (39\%). Within the limits of this study, it can be concluded that awareness about different management of jaw fractures among dental students is moderate and this may affect the healing period of osteoporotic wounds. It is important for every dentist to have a basic understanding of jaw fractures resulting from osteoporotic patients and its management to provide a proper diagnosis and treatment plan for patients with such conditions

KEY WORDS: FRACTURE; JAW; MANDIBLE; OSTEOPOROTIC.

\section{ARTICLE INFORMATION}

*Corresponding Author: dhanraj@saveetha.com

Received 18th June 2020 Accepted after revision 11th August 2020

Print ISSN: 0974-6455 Online ISSN: 2321-4007 CODEN: BBRCBA

Thomson Reuters ISI Web of Science Clarivate Analytics USA and Crossref Indexed Journal

\section{Clarivate}

NAAS Journal Score 2020 (4.31) SJIF: 2020 (7.728)

A Society of Science and Nature Publication,

Bhopal India 2020. All rights reserved.

Online Contents Available at: http//www.bbrc.in/

Doi: http://dx.doi.org/10.21786/bbrc/13.7/30 


\section{INTRODUCTION}

Osteoporosis is one of the common metabolic bone diseases with approximately 5\% rate of occurrence globally (Kyrgidis et al., 2011; Cooper, Campion and Melton, 1992; Reginster and Burlet, 2006). It is often characterized by reduced bone mass, bone fragility due to microarchitectural weakening and high risk of fracture (Gulsahi, 2015; Yamada et al., 2015) It is considered as a major public health concern seen in both genders, particularly females affecting one in three women and one in five men over the age of 50 (Kyrgidis et al., 2011; Reginster and Burlet, 2006; Gulsahi, 2015; Toumba and Skordis, 2010). Women usually show significant estrogenrelated bone loss following menopause which can be seen mainly in the trabecular bone resulting in loss of both trabecular and cortical bone in the later stages (Gulsahi, 2015; Hassani-Nejad et al., 2013). Previous studies have reported that a considerable number of osteoporotic patients will sustain one or more fragility fractures in their lifetime (Reginster and Burlet, 2006; Cooper, Campion and Melton, 1992; Melton et al., 2005).

In osteoporotic patients, resorptive activity often takes place in the mandibular cortical bone which results in reduced thickness of the bone with a highly porous inferior border (Gulsahi, 2015). Various studies have reported on the relationship between osteoporosis and bone loss in the jaw. In most cases of osteoporosis, patients are usually asymptomatic until a fracture takes place making it difficult for treatment which explains the low number of patients being diagnosed with such condition (Kyrgidis et al., 2011; Gulsahi, 2015; Edwards and Migliorati, 2008; Cosman et al., 2014). Osteoporosis is usually managed by treatment of osteoporotic- associated fractures, universal preventative methods and medical treatment of the underlying condition (Kyrgidis et al., 2011).

Management of jaw fractures may differ depending on the anatomical sites of the jaw due to the difference in biomechanics, treatment requirements and complications. Recent advancements in the management of jaw fractures have resulted in reduced risk of infection and biological stable fixation of bone segments, which allows for rapid bony union, proper restoration of occlusion and reduces the requirement for wire maxillomandibular fixation. Intermaxillary fixation is often done before fracture reduction which utilizes occlusion to help in anatomical reduction of the fracture (Bhagol, Singh and Singhal, 2013). Management of fracture is usually paired with antibiotic therapy to prevent the $50 \%$ chance of infection (Zallen and Curry, 1975).

Various risk factors need to be considered prior to making the treatment decision which includes age, weight, history of fracture, bone density, underlying diseases and habits(Edwards et al., 2008). Previously our department has published extensive research on various aspects of prosthetic dentistry ('Evaluation of Corrosive Behavior of Four Nickel-chromium Alloys in Artificial Saliva by Cyclic Polarization Test:An in vitro Study', 2017; Ganapathy, Kannan and Venugopalan, 2017; Jain, 2017a, 2017b; Ranganathan, Ganapathy and Jain, 2017; Ariga et al., 2018; Gupta, Ariga and Deogade, 2018; Anbu et al., 2019; Ashok and Ganapathy, 2019; Duraisamy et al., 2019; Varghese, Ramesh and Veeraiyan, 2019), this vast research experience has inspired us to research the association of mandibular fracture with osteoporosis and its management.

Table 1. Table showing the percentage results of responses for the questions related to the awareness of the management of jaw fractures in osteoporotic wounds among dental students.

\begin{tabular}{|c|c|c|c|}
\hline No. & Question & Response & Percentage (\%) \\
\hline 1. & $\begin{array}{l}\text { Which of the following is the } \\
\text { most common physical } \\
\text { finding of jaw fracture? }\end{array}$ & $\begin{array}{c}\text { Change in occlusion } \\
\text { Abnormal mandibular } \\
\text { range of motion and deviation } \\
\text { Sublingual ecchymosis } \\
\text { Bony deformity } \\
\text { Neurosensory disturbance }\end{array}$ & $\begin{array}{l}23 \\
20 \\
17 \\
19 \\
21\end{array}$ \\
\hline 2. & $\begin{array}{l}\text { Which of the following } \\
\text { is recommended for the } \\
\text { management of comminuted } \\
\text { fracture in the mandible? }\end{array}$ & $\begin{array}{c}\text { Compression plates } \\
\text { Reconstruction plates } \\
\text { Miniplates }\end{array}$ & $\begin{array}{l}10 \\
74 \\
16\end{array}$ \\
\hline 3. & $\begin{array}{c}\text { What is the most significant } \\
\text { advantage of locking } \\
\text { reconstruction plates? }\end{array}$ & $\begin{array}{c}\text { No intimate contact with } \\
\text { the underlying bones } \\
\text { in all areas } \\
\text { Good stability by functioning } \\
\text { as internal fixators } \\
\text { No expansion }\end{array}$ & $\begin{array}{l}42 \\
36\end{array}$ \\
\hline
\end{tabular}




\begin{tabular}{|c|c|c|c|}
\hline 4. & $\begin{array}{l}\text { In a surgical technique, } \\
\text { which of the following } \\
\text { is the most common } \\
\text { approach for jaw fracture? }\end{array}$ & $\begin{array}{l}\text { Transoral } \\
\text { Vestibular } \\
\text { Transfacial }\end{array}$ & $\begin{array}{l}39 \\
27 \\
34\end{array}$ \\
\hline 5. & $\begin{array}{l}\text { Which of the following is } \\
\text { the absolute indication } \\
\text { for open reduction } \\
\text { of condylar fractures? }\end{array}$ & $\begin{array}{l}\text { Bilateral condyle fractures } \\
\text { in an edentulous patient } \\
\text { Lateral extracapsular } \\
\text { displacement of the condyle } \\
\text { Bilateral condylar fractures } \\
\text { associated with comminuted } \\
\text { midface fractures }\end{array}$ & $\begin{array}{l}33 \\
39\end{array}$ \\
\hline 6. & $\begin{array}{l}\text { Which of the following is } \\
\text { the most common incision } \\
\text { for open reduction } \\
\text { of condyle fracture? }\end{array}$ & $\begin{array}{l}\text { Preauricular incision } \\
\text { Submandibular incision } \\
\text { Intraoral incision }\end{array}$ & $\begin{array}{l}77 \\
10 \\
13\end{array}$ \\
\hline 7. & $\begin{array}{l}\text { In the management of } \\
\text { edentulous mandible, } \\
\text { which of the following } \\
\text { techniques has lower } \\
\text { risk of complications? }\end{array}$ & $\begin{array}{l}\text { Closed reduction with } \\
\text { the use of prosthesis } \\
\text { Open reduction with } \\
\text { internal fixation }\end{array}$ & $\begin{array}{l}32 \\
68\end{array}$ \\
\hline 8. & $\begin{array}{l}\text { Which of the following is } \\
\text { the most common complication } \\
\text { of mandibular fractures? }\end{array}$ & $\begin{array}{l}\text { Malocclusion and malunion } \\
\text { Infection } \\
\text { Nerve injury }\end{array}$ & $\begin{array}{l}12 \\
71 \\
17\end{array}$ \\
\hline 9. & $\begin{array}{l}\text { Which of the following is } \\
\text { associated with the } \\
\text { least complications in } \\
\text { the treatment of } \\
\text { angle fractures? }\end{array}$ & $\begin{array}{c}\text { Extraoral ORIF with } \\
\text { a large reconstruction } \\
\text { plate } \\
\text { Intraoral ORIF using } \\
\text { a single lag screw } \\
\text { Intraoral ORIF using } \\
\text { two 2-4mm mandibular } \\
\text { compression plate }\end{array}$ & 33 \\
\hline 10. & $\begin{array}{l}\text { Which of the following is } \\
\text { associated with the } \\
\text { highest rate of complications? }\end{array}$ & $\begin{array}{l}\text { Mandibular body } \\
\text { fractures } \\
\text { Angle fractures } \\
\text { Condylar fractures }\end{array}$ & $\begin{array}{l}34 \\
37 \\
29\end{array}$ \\
\hline
\end{tabular}

\section{MATERIAL AND METHODS}

A questionnaire-based study was conducted involving students of Saveetha Dental College and Hospital, Chennai, India for a period of January 2020 to March 2020. Two examiners were involved in this study. A total of 100 participants took part in the survey. The inclusion criteria of this study were dental students ranging from third years to post-graduates with personal experiences of working in a dental setting. First and second year dental students and non-dental students were excluded from this study. All the participants were provided with a list of 10 questions related to the management of jaw fractures in osteoporotic patients. Data was collected and statistical analysis was done. Tabulation and analysis of the collected data were done using Statistical Package for Social Sciences for Windows version 23.0 (SPSS Inc., Chicago, IL, USA). Descriptive analysis was done to assess the awareness of dental students on the management of jaw fractures in osteoporotic wounds based on their responses for each question provided.

\section{RESULTS AND DISCUSSION}

Our present study reveals that most of participants have chosen the change in occlusion (23\%) as the most common physical finding of jaw fracture, followed by neurosensory disturbance (21\%), abnormal mandibular motion and deviation (20\%), bony deformity (19\%) and sublingual ecchymosis (17\%) respectively. [Figure 1] A report by Bhagol et al., states that the change in occlusion is undoubtedly the most common clinical feature seen in patients with jaw fracture. The report also confirms other findings such as neurosensory disturbances that occurs when the fracture crosses an area of the mandible close to the inferior alveolar nerve, abnormal mandibular range of motion or deviation normally expressed by the incapability of patients to close the mouth completely and sublingual ecchymosis as highly indicative of mandibular fracture (Bhagol, Singh and Singhal, 2013).

It can be seen that most of the participants agreed that the comminuted fracture of the mandible can be best treated using reconstruction plates which accounts for $74 \%$ of them, followed by miniplates (16\%) and 
compression plates (10\%) respectively. [Figure 2] It was reported that reconstruction plates are often preferred in the treatment of comminuted fracture and may act as a bridge for continuity gaps due to its rigidity and ability to adapt properly to the underlying bones. Reconstruction plates are placed along with their corresponding screws (2.3-3.0mm) (Bhagol, Singh and Singhal, 2013). Another study also describes the use of larger and highly rigid plates for the treatment of comminuted fracture and continuity gaps (Herford and Ellis, 1998; Edwards and David, 1996).

Figure 1: Bar chart showing the responses to Question 1 , "Which of the following is the most common physical finding in patients with jaw fracture?". X axis represents the multiple answers provided. $\mathrm{Y}$ axis represents the number of individuals with each answer (Blue). Most of the participants have chosen the change in occlusion (23\%) as the most common physical finding of jaw fracture, followed by neurosensory disturbance (21\%), abnormal mandibular motion and deviation (20\%), bony deformity (19\%) and sublingual ecchymosis (17\%) respectively.

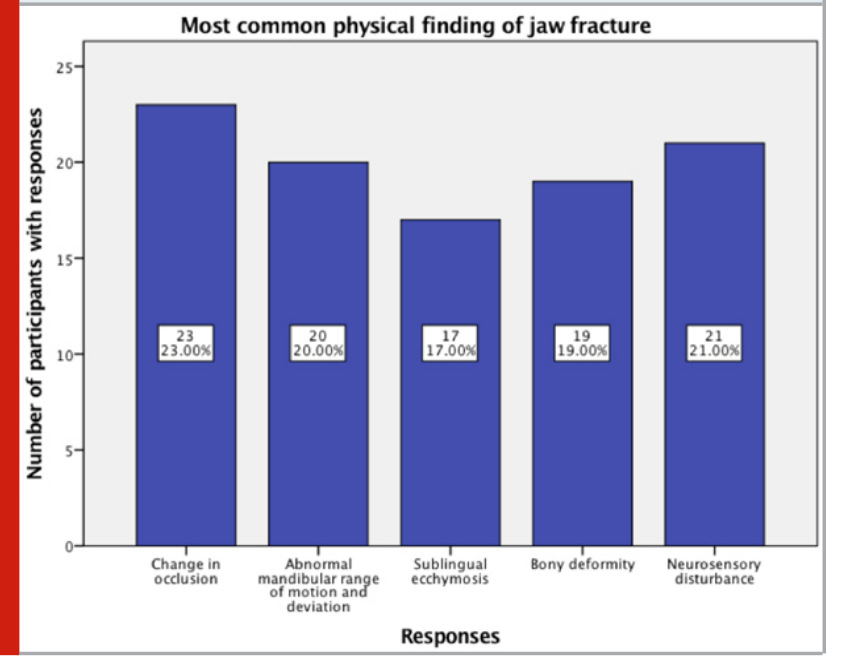

Most of the participants believe that the absence of intimate contact with the underlying bone in all areas is the best feature of the plate (42\%), while $36 \%$ of them have chosen the ability of locking reconstruction plate to function as internal fixators providing good stability and the remaining 22\% suggested the absence of expansion screw as the main advantage of the plate. [Figure 3] This result is further supported by another study by Bhagol et al., which confirms that locking reconstruction plates do not require close contact with the underlying bones in all areas (Bhagol, Singh and Singhal, 2013).

Transoral approach is commonly done for the treatment of jaw fracture according to 39\% of the participants, $34 \%$ have chosen transfacial approach and vestibular approach are selected by the other $27 \%$ of the participants. [Figure 4] Most fractures can be easily managed by transoral incision except for condyle fracture as described in a previous study because it provides good access and visibility for fracture reduction and fixation in a surgical technique (Bhagol, Singh and Singhal, 2013).

Figure 2: Bar chart showing the responses to Question 2 , "Which of the following is recommended for the management of comminuted fracture in the mandible?". $\mathrm{X}$ axis represents the multiple answers provided. $\mathrm{Y}$ axis represents the number of individuals with each answer (Purple). Most of the participants agreed that the comminuted fracture of the mandible can be best treated using reconstruction plates (74\%), followed by miniplates $(16 \%)$ and compression plates $(10 \%)$ respectively.

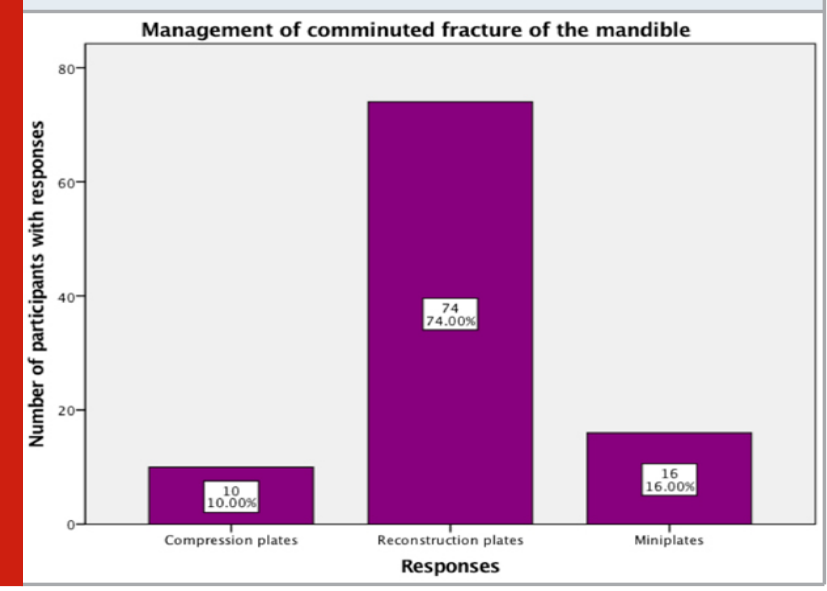

Figure 3: Bar chart showing the responses to Question 3, "What is the most significant advantage of locking reconstruction plates?". X axis represents the multiple answers provided. $\mathrm{Y}$ axis represents the number of individuals with each answer (Green). Majority of the participants believe that the absence of intimate contact with the underlying bone in all areas is the best feature of the plate $(42 \%)$, while some of them have chosen the ability of locking reconstruction plate to function as internal fixators providing good stability (36\%) and the remaining participants suggested the absence of expansion screw as the main advantage of the plate $(22 \%)$.

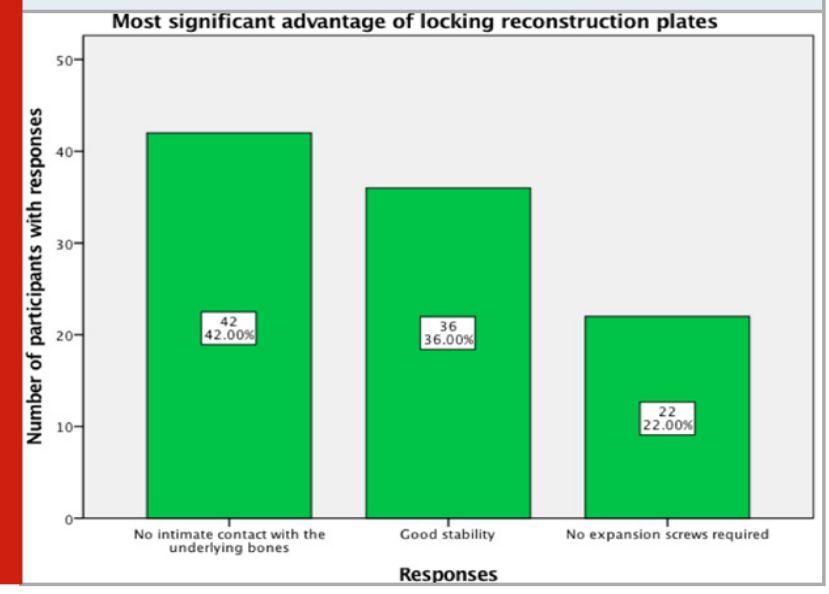


Figure 4: Bar chart showing the responses to Question 4, "In a surgical technique, which of the following is the most common approach for jaw fracture?”. X axis represents the multiple answers provided. $\mathrm{Y}$ axis represents the number of individuals with each answer (Gold). Transoral approach is considered as the most common approach for surgical technique in the treatment of jaw fracture (39\%), followed by transfacial approach (34\%) and vestibular approach $(27 \%)$ respectively.

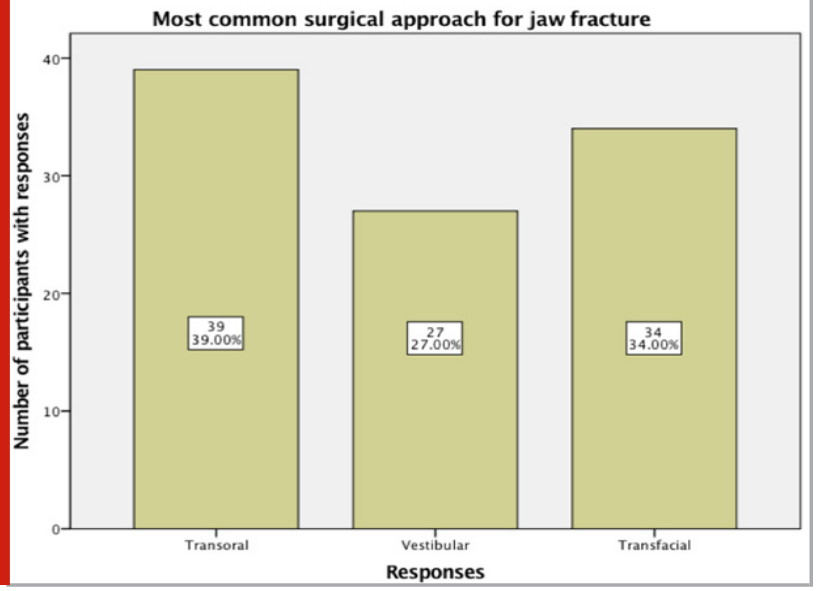

Figure 5: Bar chart showing the responses to Question 5 , "Which of the following is the absolute indication for open reduction of condylar fractures?”. X axis represents the multiple answers provided. $\mathrm{Y}$ axis represents the number of individuals with each answer (Orange). Lateral extracapsular displacement of the condyle is selected as the absolute indication for open reduction in the treatment of condyle fracture (39\%), followed by bilateral condyle fractures in edentulous patients (33\%) and bilateral condylar fracture with comminuted midface fracture $(28 \%)$ respectively.

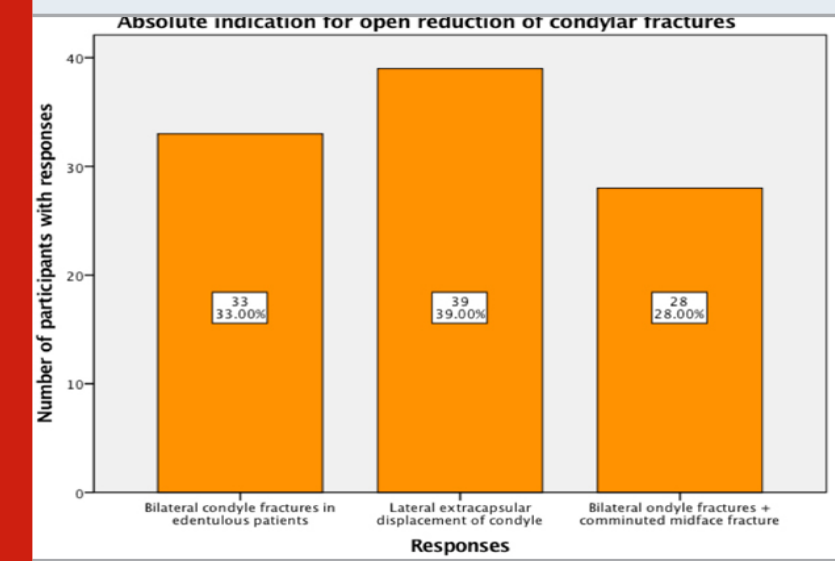

Our study shows that the lateral extracapsular displacement of the condyle is selected as the absolute indication for open reduction in the treatment of condyle fracture according to 39\% of the participants, followed by bilateral condyle fractures in edentulous patients (33\%) and bilateral condyle fracture with comminuted midface fracture (28\%). [Figure 5] A previous study reported that lateral extracapsular displacement of condyle is considered as one of the absolute indications for open reduction of condyle fracture while bilateral condyle fractures in edentulous patients and bilateral condyle fracture with comminuted midface fracture are grouped as relative indications for open reduction of condyle fractures (Hazrati, Zide and Kent, 1984; Bhagol, Singh and Singhal, 2013).

Figure 6: Bar chart showing the responses to Question 6, "Which of the following is the most common incision for open reduction of condyle fracture?". X axis represents the multiple answers provided. $Y$ axis represents the number of individuals with each answer (Red). Most of the participants agreed that preauricular incision is the best option for open reduction of condyle fracture (77\%), followed by intraoral incision (13\%) and submandibular incision (10\%) respectively.

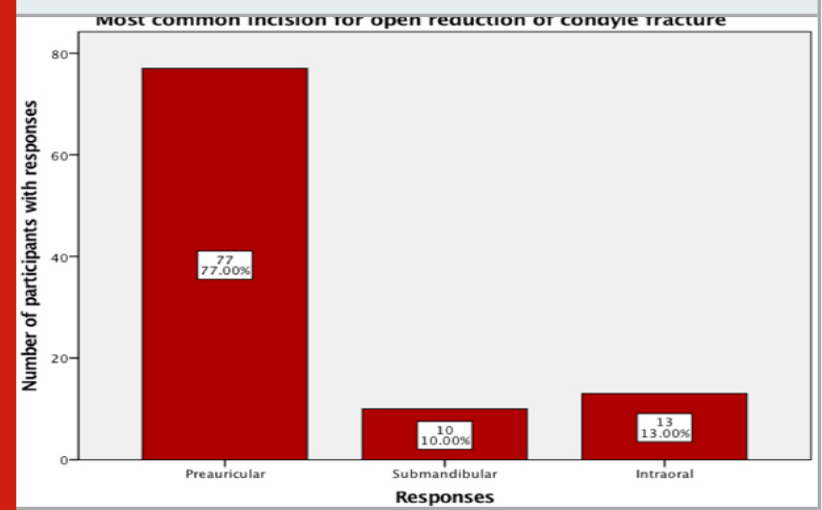

Most of the participants agreed that preauricular incision is the best option for open reduction of condyle fracture as chosen by 77\% of them, followed by intraoral incision (13\%) and submandibular incision (10\%). [Figure 6] Most common surgical approaches in the treatment of mandibular fracture are reported to be retromandibular, submandibular and preauricular approaches (Bhagol, Singh and Singhal, 2013). In the treatment of condyle fracture, preauricular incision is the most common approach providing direct access to the temporomandibular joint (TMJ) (Dergin, Emes and Aybar, 2019; Ellis and Dean, 1993). Submandibular approach can be done to access the TMJ indirectly while intraoral incision is usually done at the sigmoid notch (Zachariades et al., 2006; Khelemsky, Moubayed and Buchbinder, 2016).

It can be seen that $68 \%$ of the participants believe that open reduction with internal fixation can be done with lesser complications in the management of edentulous mandible compared to closed reduction with the use of prosthesis chosen by 32\% of them. [Figure 7] A previous study reveals lesser complications seen in patients treated by transfacial open reduction and internal fixation than those who underwent closed reduction technique showing complications such as delayed fibrous union $(15 \%)$ and union defect (26\%) in the management of 
edentulous fracture (Bhagol, Singh and Singhal, 2013; Bruce and Ellis, 1993).

Figure 7: Bar chart showing the responses to Question 7, "In the management of edentulous mandible, which of the following techniques has lower risk of complications?". $\mathrm{X}$ axis represents the multiple answers provided. $\mathrm{Y}$ axis represents the number of individuals with each answer (Yellow). Most of the participants believe that open reduction with internal fixation can be done with lesser complications (68\%) in the management of edentulous mandible compared to closed reduction with the use of prosthesis (32\%).

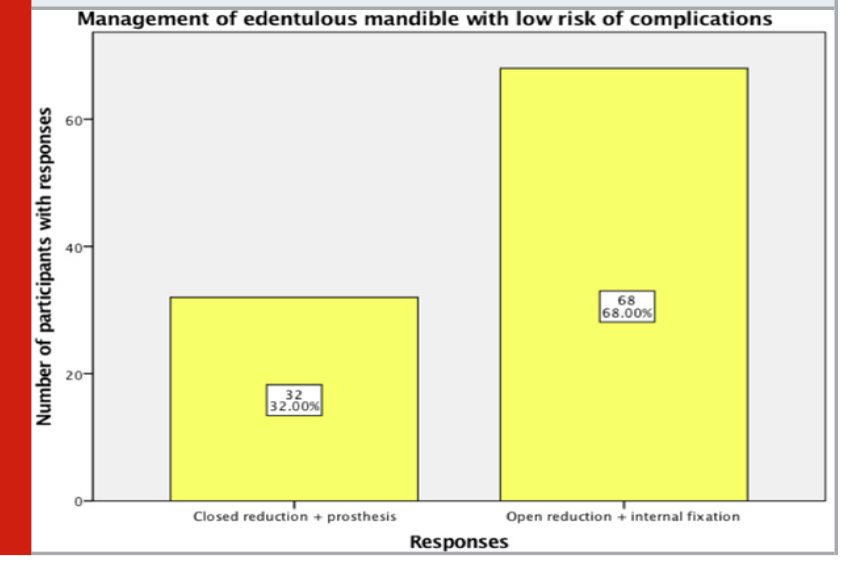

Figure 8: Bar chart showing the responses to Question 8, "Which of the following is the most common complication of mandibular fractures?". X axis represents the multiple answers provided. $\mathrm{Y}$ axis represents the number of individuals with each answer (Pink). A significant number of participants agreed on infections being the most common complication of mandibular fractures (71\%). The remaining participants have chosen nerve injury $(17 \%)$ and malocclusion or malunion $(12 \%)$ as the main complications of jaw fracture.

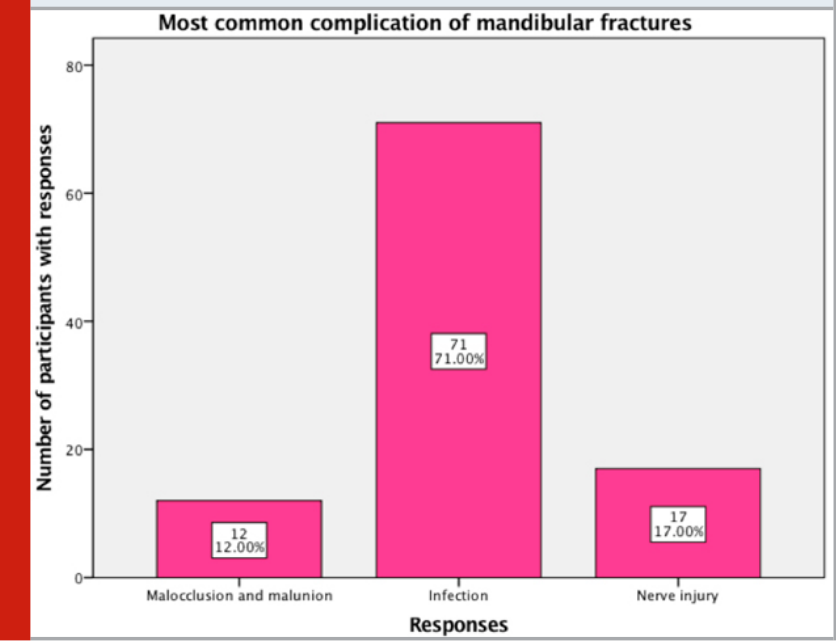

A significant number of participants agreed on infections being the most common complication of mandibular fractures as chosen by $71 \%$ of them. The remaining participants have chosen nerve injury (17\%) and malocclusion or malunion (12\%) as the main complications of jaw fracture. [Figure 8] It was reported that infections are the most commonly reported complication of mandibular fracture seen in about $0.4 \%$ - 32\% of patients. According to Zallen and Curry et al., patients who do not receive antibiotic therapy following fracture treatment are often associated with 50\% risk of infection compared to the $6 \%$ risk of infection seen in patients receiving antibiotic therapy (Zallen and Curry, 1975). Problems with malunion or malocclusion was reported in approximately $0 \%-4.2 \%$ of cases (MoultonBarrett et al., 1998). Nerve injury is often reported in 11\% - 59\% cases of displaced mandibular fractures, mainly involving inferior alveolar nerve and mental nerve (Thaller, 1994; Iizuka and Lindqvist, 1991; Marchena, Padwa and Kaban, 1998).

Figure 9: Bar chart showing the responses to Question 9, "Which of the following is associated with the least complications in the treatment of angle fractures?". X axis represents the multiple answers provided. Y axis represents the number of individuals with each answer (Turquoise). Majority of the participants have chosen extraoral ORIF with a large reconstruction plate (39\%) as the treatment of angle fractures with lesser complications compared to intraoral ORIF using a single lag screw (33\%) and intraoral ORIF using two 2-4mm mandibular compression plate $(28 \%)$.

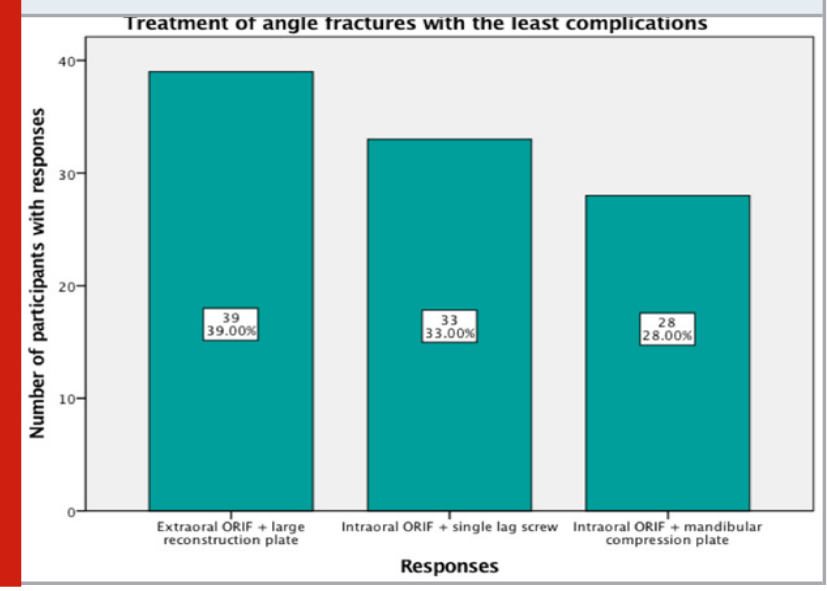

It can be seen that 39\% of the participants have chosen extraoral ORIF with a large reconstruction plate as the treatment of angle fractures with lesser complications compared to intraoral ORIF using a single lag screw (33\%) and intraoral ORIF using two 2-4mm mandibular compression plate (28\%) as selected by the other participants. [Figure 9] It has been reported previously that extraoral ORIF with a reconstruction plate is associated with the least complications (7.5\%) compared to the other two methods in the treatment of angle fractures (Ellis, 1999).

Most of the participants mentioned angle fracture having the highest rate of complications selected by $37 \%$ of them as compared to mandibular body fracture (34\%) 
and condyle fracture (29\%). [Figure 10] A previous report describes the angle of mandible as a fragile area compared to the mandibular body and ramus seen anterior and posterior to the angle respectively (Schubert, Kobienia and Pollock, 1997). It is further complicated by the movement of the elevator muscles and depressor muscles with opposing forces leading to highest risk of complications in angle fractures (Juniper and Awty, 1973).

Figure 10: Bar chart showing the responses to Question 10, "Which of the following is associated with the highest rate of complications?". $X$ axis represents the multiple answers provided. $\mathrm{Y}$ axis represents the number of individuals with each answer (Brown). Most of the participants have selected angle fracture (37\%) with the highest rate of complications when compared to mandibular body fracture $(34 \%)$ and condyle fracture (29\%).

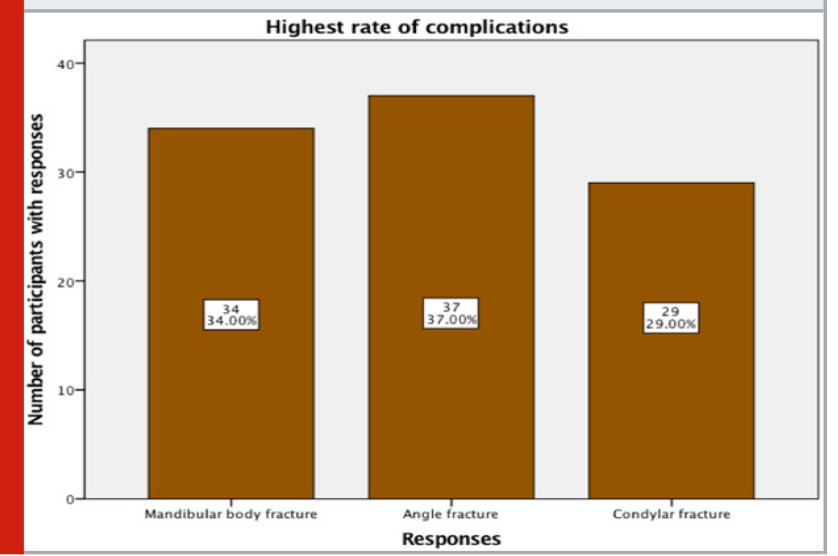

Facial skeleton is often the focus of interest in patients with osteoporosis. Mandible is one of the principal skeleton components of the face in which fracture of this essential bone may affect both esthetic and function of an individual. Proper diagnosis and early prevention can be achieved by the cooperation from both dentists and physicians. Early recognition and rapid intervention in the management of jaw fractures in osteoporotic patients are important for a multidisciplinary approach.

\section{CONCLUSION}

Within the limits of this study, it can be concluded that awareness about different management of jaw fractures among dental students is moderate and this may affect the healing period of osteoporotic wounds. It is important for every dentist to have a basic understanding of jaw fractures resulting from osteoporotic wounds and its management to provide a proper diagnosis and treatment plan for patients with such conditions.

\section{ACKNOWLEDGEMENTS}

We would like to thank Saveetha Dental College and Hospital for the contributions and involvement through this study.

Conflict of Interest: There was no conflict of interest.

\section{REFERENCES}

Anbu, R. T. et al. (2019) 'Comparison of the Efficacy of Three Different Bone Regeneration Materials: An Animal Study', European journal of dentistry, 13(1), pp. 22-28.

Ariga, P. et al. (2018) 'Determination of Correlation of Width of Maxillary Anterior Teeth using Extraoral and Intraoral Factors in Indian Population: A Systematic Review', World Journal of Dentistry, 9(1), pp. 68-75.

Ashok, V. and Ganapathy, D. (2019) 'A geometrical method to classify face forms', Journal of oral biology and craniofacial research, 9(3), pp. 232-235.

Bhagol, A., Singh, V. and Singhal, R. (2013) 'Management of Mandibular Fractures', A Textbook of Advanced Oral and Maxillofacial Surgery. doi: 10.5772/53854.

Bruce, R. A. and Ellis, E. (1993) 'The second Chalmers J. Lyons academy study of fractures of the edentulous mandible', Journal of Oral and Maxillofacial Surgery, pp. 904-911. doi: 10.1016/s0278-2391(10)80113-2.

Cooper, C., Campion, G. and Melton, L. J. (1992) 'Hip fractures in the elderly: A world-wide projection', Osteoporosis International, pp. 285-289. doi: 10.1007/ bf01623184.

Cosman, F. et al. (2014) 'Clinician's Guide to Prevention and Treatment of Osteoporosis', Osteoporosis International, pp. 2359-2381. doi: 10.1007/s00198-0142794-2.

Dergin, G., Emes, Y. and Aybar, B. (2019) 'Evaluation and Management of Mandibular Fracture', Trauma in Dentistry. doi: 10.5772/intechopen.83024.

Duraisamy, R. et al. (2019) 'Compatibility of Nonoriginal Abutments With Implants: Evaluation of Microgap at the Implant-Abutment Interface, With Original and Nonoriginal Abutments', Implant dentistry, 28(3), pp. 289-295.

Edwards, B. J. et al. (2008) 'Pharmacovigilance and reporting oversight in US FDA fast-track process: bisphosphonates and osteonecrosis of the jaw', The Lancet Oncology, pp. 1166-1172. doi: 10.1016/s14702045(08)70305-X.

Edwards, B. J. and Migliorati, C. A. (2008) 'Osteoporosis and its implications for dental patients', Journal of the American Dental Association , 139(5), pp. 545-52; quiz 625-6.

Edwards, T. J. and David, D. J. (1996) 'A comparative study of miniplates used in the treatment of mandibular fractures', Plastic and reconstructive surgery, 97(6), pp. 1150-1157.

Ellis, E. (1999) 'Treatment methods for fractures of the mandibular angle', International Journal of Oral and Maxillofacial Surgery, pp. 243-252. doi: 10.1016/ s0901-5027(99)80152-0.

Ellis, E. and Dean, J. (1993) 'Rigid fixation of mandibular condyle fractures', Oral Surgery, Oral Medicine, Oral Pathology, pp. 6-15. doi: 10.1016/0030- 
4220(93)90285-c.

'Evaluation of Corrosive Behavior of Four Nickelchromium Alloys in Artificial Saliva by Cyclic Polarization Test:An in vitro Study' (2017) World Journal of Dentistry, 8(6), pp. 477-482.

Ganapathy, D. M., Kannan, A. and Venugopalan, S. (2017) 'Effect of Coated Surfaces influencing Screw Loosening in Implants: A Systematic Review and Meta-analysis', World Journal of Dentistry, 8(6), pp. 496-502.

Gulsahi, A. (2015) 'Osteoporosis and jawbones in women', Journal of International Society of Preventive Ct Community Dentistry, 5(4), pp. 263-267.

Gupta, P., Ariga, P. and Deogade, S. C. (2018) 'Effect of Monopoly-coating Agent on the Surface Roughness of a Tissue Conditioner Subjected to Cleansing and Disinfection: A Contact Profilometric Study', Contemporary clinical dentistry, 9(Suppl 1), pp. S122S126.

Hassani-Nejad, A. et al. (2013) 'Mandibular trabecular bone as fracture indicator in 80-year-old men and women', European journal of oral sciences, 121(6), pp. 525-531.

Hazrati, E., Zide, M. F. and Kent, J. N. (1984) 'Indications for open reduction of mandibular condyle fractures', Plastic and Reconstructive Surgery, p. 162. doi: 10.1097/00006534-198401000-00062.

Herford, A. S. and Ellis, E. (1998) 'Use of a locking reconstruction bone plate/screw system for mandibular surgery', Journal of Oral and Maxillofacial Surgery, pp. 1261-1265. doi: 10.1016/s0278-2391(98)90605-x.

Iizuka, T. and Lindqvist, C. (1991) 'Sensory disturbances associated with rigid internal fixation of mandibular fractures', Journal of oral and maxillofacial surgery: official journal of the American Association of Oral and Maxillofacial Surgeons, 49(12), pp. 1264-1268.

Jain, A. R. (2017a) 'Clinical and Functional Outcomes of Implant Prostheses in Fibula Free Flaps', World Journal of Dentistry, 8(3), pp. 171-176.

Jain, A. R. (2017b) 'Prevalence of Partial Edentulousness and Treatment needs in Rural Population of South India', World Journal of Dentistry, 8(3), pp. 213-217. Juniper, R. P. and Awty, M. D. (1973) 'The immobilization period for fractures of the mandibular body', Oral surgery, oral medicine, and oral pathology, 36(2), pp. 157-163.

Khelemsky, R., Moubayed, S. P. and Buchbinder, D. (2016) 'What is the evidence for open versus closed treatment of mandibular condylar fractures in adults?', The Laryngoscope, 126(11), pp. 2423-2425.

Kyrgidis, A. et al. (2011) 'The facial skeleton in patients with osteoporosis: a field for disease signs and treatment complications', Journal of osteoporosis, 2011, p. 147689.

Marchena, J. M., Padwa, B. L. and Kaban, L. B. (1998) 'Sensory abnormalities associated with mandibular fractures: incidence and natural history', Journal of oral and maxillofacial surgery: official journal of the American Association of Oral and Maxillofacial Surgeons, 56(7), pp. 822-5; discussion 825-6.

Melton, L. J. et al. (2005) 'How Many Women Have Osteoporosis?', Journal of Bone and Mineral Research, pp. 886-892. doi: 10.1359/jbmr.2005.20.5.886.

Moulton-Barrett, R. et al. (1998) 'Complications of mandibular fractures', Annals of plastic surgery, 41(3), pp. 258-263.

Ranganathan, H., Ganapathy, D. M. and Jain, A. R. (2017) 'Cervical and Incisal Marginal Discrepancy in Ceramic Laminate Veneering Materials: A SEM Analysis', Contemporary clinical dentistry, 8(2), pp. 272-278.

Reginster, J.-Y. and Burlet, N. (2006) 'Osteoporosis: a still increasing prevalence', Bone, 38(2 Suppl 1), pp. S4-9.

Schubert, W., Kobienia, B. J. and Pollock, R. A. (1997) 'Cross-sectional area of the mandible', Journal of oral and maxillofacial surgery: official journal of the American Association of Oral and Maxillofacial Surgeons, 55(7), pp. 689-92; discussion 693.

Thaller, S. R. (1994) 'Management of mandibular fractures', Archives of otolaryngology--head \&t neck surgery, 120(1), pp. 44-48.

Toumba, M. and Skordis, N. (2010) 'Osteoporosis syndrome in thalassaemia major: an overview', Journal of osteoporosis, 2010, p. 537673.

Varghese, S. S., Ramesh, A. and Veeraiyan, D. N. (2019) 'Blended Module-Based Teaching in Biostatistics and Research Methodology: A Retrospective Study with Postgraduate Dental Students', Journal of dental education, 83(4), pp. 445-450.

Yamada, S. et al. (2015) 'Panoramic radiography measurements, osteoporosis diagnoses and fractures in Japanese men and women', Oral Diseases, pp. 335-341. doi: 10.1111/odi.12282.

Zachariades, N. et al. (2006) 'Fractures of the mandibular condyle: a review of 466 cases. Literature review, reflections on treatment and proposals', Journal of cranio-maxillo-facial surgery: official publication of the European Association for Cranio-Maxillo-Facial Surgery, 34(7), pp. 421-432.

Zallen, R. D. and Curry, J. T. (1975) 'A study of antibiotic usage in compound mandibular fractures', Journal of oral surgery , 33(6), pp. 431-434. 